\title{
Pleiotropic Mitochondria: The Influence of Mitochondria on Neuronal Development and Disease
}

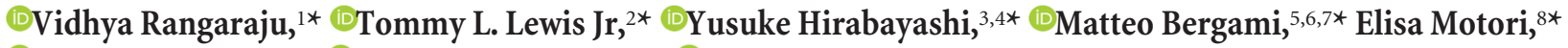 \\ (D) Romain Cartoni, $9,10 *$ (DSeok-Kyu Kwon, ${ }^{11}$ and (D) Julien Courchet ${ }^{12}$ \\ ${ }^{1}$ Max Planck Institute for Brain Research, Frankfurt 60438, Germany, ${ }^{2}$ Aging \& Metabolism Program, Oklahoma Medical Research Foundation, Oklahoma \\ City, Oklahoma 73104, ${ }^{3}$ Department of Chemistry and Biotechnology, Graduate School of Engineering, University of Tokyo, 113-8656 Tokyo, Japan, ${ }^{4}$ Japan \\ Science and Technology Agency, Precursory Research for Embryonic Science and Technology, 332-0012 Saitama, Kawaguchi, Japan, ${ }^{5}$ Cologne Excellence \\ Cluster on Cellular Stress Responses in Aging-Associated Diseases, University Hospital Cologne, Cologne D-50931, Germany, ${ }^{6}$ Institute of Genetics, \\ University of Cologne, Cologne D-50674, Germany, ${ }^{7}$ Center for Molecular Medicine, Cologne D-50931, Germany, ${ }^{8}$ Max Planck Institute for Biology of \\ Ageing, Cologne D-50931, Germany, ${ }^{9}$ Department of Pharmacology and Cancer Biology, Duke University School of Medicine, Durham, North Carolina \\ 27710, ${ }^{10}$ Department of Ophthalmology, Duke University School of Medicine, Durham, North Carolina 27710, ${ }^{11}$ Korea Institute of Science and Technology, \\ Center for Functional Connectomics, Brain Science Institute, Seoul, South Korea 02792, and ${ }^{12}$ Université Claude Bernard Lyon 1, Centre National de la \\ Recherche Scientifique Unité Mixte de Recherche-5310, Institut National de la Santé et de la Recherche Médicale U-1217, Institut NeuroMyoGène, F-69622, \\ Villeurbanne, France
}

Mitochondria play many important biological roles, including ATP production, lipid biogenesis, ROS regulation, and calcium clearance. In neurons, the mitochondrion is an essential organelle for metabolism and calcium homeostasis. Moreover, mitochondria are extremely dynamic and able to divide, fuse, and move along microtubule tracks to ensure their distribution to the neuronal periphery. Mitochondrial dysfunction and altered mitochondrial dynamics are observed in a wide range of conditions, from impaired neuronal development to various neurodegenerative diseases. Novel imaging techniques and genetic tools provide unprecedented access to the physiological roles of mitochondria by visualizing mitochondrial trafficking, morphological dynamics, ATP generation, and ultrastructure. Recent studies using these new techniques have unveiled the influence of mitochondria on axon branching, synaptic function, calcium regulation with the ER, glial cell function, neurogenesis, and neuronal repair. This review provides an overview of the crucial roles played by mitochondria in the CNS in physiological and pathophysiological conditions.

Key words: mitochondria; energy; synaptic function; neuronal development; neurodegenerative disease

\section{Introduction}

The regulation and maintenance of cellular metabolism are a critical challenge for the nervous system. The metabolic cost of performing and maintaining basic neural functions is disproportionately high, primarily due to the highly complex morphology of neurons, their finely regulated transmembrane ion gradients,

\footnotetext{
Received July 2, 2019; revised Aug. 9, 2019; accepted Aug. 10, 2019.

V.R. was supported by a European Molecular Biology Organization Long-Term Fellowship and the European Union's Horizon 2020 research and innovation program (Marie Sklowdoska-Curie Grant Agreement 65770). T.L.L. was supported by the Presbyterian Health Foundation and National Institutes of Health 2P20 GM103636-06. Y.H. was supported by Japan Science and Technology Agency JPMJPR16F7. M.B. was supported by Deutsche Forschungsgemeinschaft SFB1218 A07 and European Research Council ERC-StG-2015 (Grant 67844). E.M. is the recipient of Advanced Postdoc Grant Deutsche Forschungsgemeinschaft SFB1218. R.C. is a Whithead Scholar and is supported by a Kahn Neurodegeneration Award. J.C. was supported by the European Research Council ERC-StG-2015 (Grant 678302). S.-K.K. was supported by the Brain Research Program and the Bio \& Medical Technology Development Program of the National Research Foundation funded by the Korean government (2017M3C7A1043838 and 2019M3E5D2A01063794), and the Korea Institute of Science and Technology Institutional Program (2E29180 and 2V07340). We apologize to colleagues whose original work could not be cited in this review due to space constraints.

The authors declare no competing financial interests.

*V.R., T.L.L., Y.H., M.B., E.M., and R.C. contributed equally to this work.

Correspondence should be addressed to Seok-Kyu Kwon at skkwon@kist.re.kr or Julien Courchet at julien.courchet@univ-lyon1.fr.

https://doi.org/10.1523/JNEUROSCl.1157-19.2019

Copyright $\odot 2019$ the authors
}

and the constant activity of billions of synapses. It is classically estimated that the human brain is one of the most energy-taxing organs, accounting for $20 \%$ of the total energy expenditure of the body (Kety, 1957; Mink et al., 1981; Attwell and Laughlin, 2001), with even higher metabolic requirements during development (Goyal et al., 2014; Kuzawa et al., 2014). The brain's metabolic homeostasis is heavily regulated and involves close integration of metabolism in neurons and glia, which together form a metabolic unit to meet the energetic needs of neurons and neural processing (Bélanger et al., 2011; Magistretti and Allaman, 2015, 2018). Neural circuits rely heavily on mitochondrial respiration, although other metabolic pathways contribute to neuronal bioenergetics as well, including neuronal glycolysis (Zala et al., 2013; Rangaraju et al., 2014; Pathak et al., 2015; Jang et al., 2016; Ashrafi et al., 2017; Díaz-García et al., 2017).

Recent studies using innovative techniques, such as optogenetics and real-time metabolic imaging, have uncovered pleiotropic roles for mitochondria spanning from neurodevelopment to neurodegeneration. These organelles, mainly acknowledged as the cell's powerhouse for producing ATP via oxidative phosphorylation, also play essential roles in calcium $\left(\mathrm{Ca}^{2+}\right)$ clearance, lipid biogenesis, and ROS regulation. A vast literature has focused on 

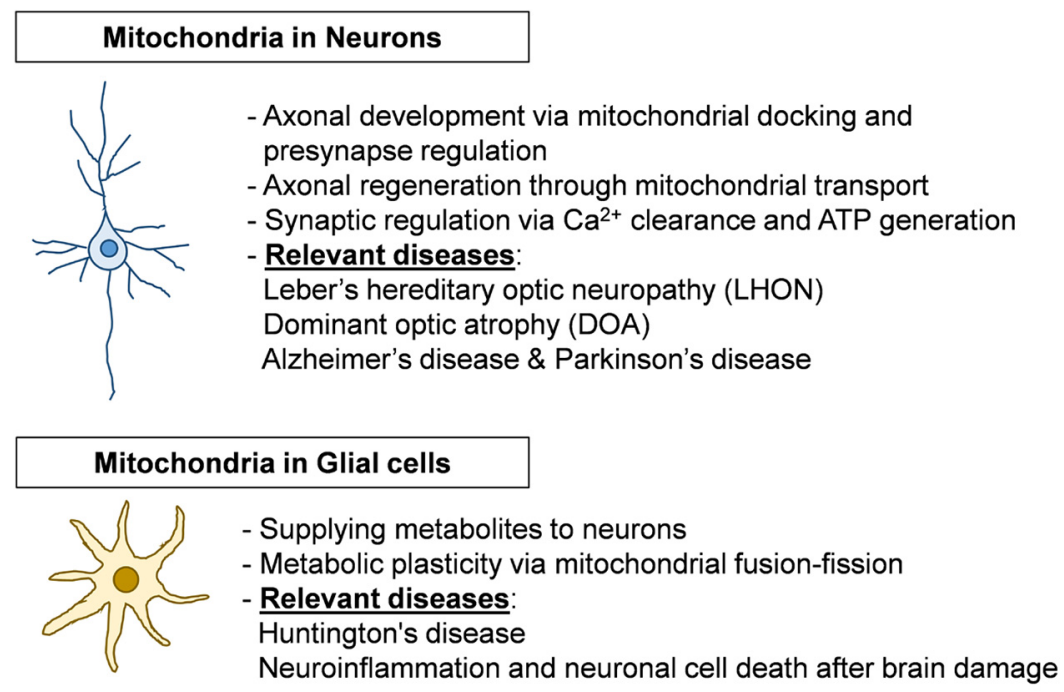
Mitochondria in Neural stem cell \&
progenitor cells

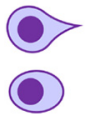

- Cell fate regulation via mitochondrial dynamics \& function
- Upregulation of mitochondrial metabolism during proliferation
- Dendritogenesis through mitochondrial network remodeling

Figure 1. Mitochondria play key roles in energy metabolism and $\mathrm{Ca}^{2+}$ regulation in various cell types of the brain. In neurons, mitochondria regulate axonal and dendritic development, axonal regeneration, and synaptic function. Glial mitochondria provide metabolites to neurons, and energy metabolism is regulated by mitochondrial morphological dynamics. In neural stem and progenitor cells, cell fate can be determined by mitochondrial fusion-fission and function. Many neurodegenerative diseases are associated with mitochondrial dysfunction.

the role of mitochondria in the brain, but recent technological advances have allowed researchers to address the specific core features of mitochondrial biology involved at various stages of a neuron's life. For instance, metabolic rewiring is increasingly recognized as a major player in the activation of quiescent neural stem cells and their proliferation. Later in development, dendritogenesis and axon outgrowth and branching are directly affected by the regulated transport, fusion-fission, and anchoring of mitochondria. In mature neurons, mitochondria contribute to synaptic transmission and plasticity through local ATP supply and $\mathrm{Ca}^{2+}$ buffering. Other brain cell types, and in particular glial cells, also supply key energy metabolites to neurons for powering synapses, and their apparent heightened metabolic plasticity renders them ideally suited to regulate multiple forms of coupling not only with neurons but also with the vasculature. It is therefore not surprising that mitochondrial dysfunction and altered mitochondrial dynamics are widely observed in conditions ranging from impaired neuronal development to various neurodegenerative diseases. Yet we have only scratched the surface of the mechanisms underlying the complex interdependence between mitochondrial and neuronal functions.

Specific aspects of neuronal bioenergetics and mitochondrial biology have been covered in detail in excellent recent reviews (Mattson et al., 2008; Chen and Chan, 2009; Schon and Przedborski, 2011; Harris et al., 2012; Sheng and Cai, 2012; Burté et al., 2015; Khacho et al., 2019). In this review, we discuss recent advances in understanding the broad range of mitochondrial functions in the nervous system during health and disease, and provide a framework for future research leading to exciting novel directions. In particular, we focus on work discussed in an accompanying Mini-Symposium presented at the 2019 Annual Meeting of the Society for Neuroscience.
The roles of mitochondria in neural circuit development

From mitochondria positioning to local metabolic function in developing neurites Neurogenesis, and the subsequent morphogenetic cascade that leads to the formation of a fully mature neuron that is integrated into a functional neural circuit, is accompanied by intense metabolic remodeling. During the transition from progenitor cells, which rely largely on glycolysis to meet their energy needs, to neurons, which are mostly dependent on oxidative metabolism, the proper localization of mitochondria becomes a critical determinant. Although the importance of mitochondrial transport has long been appreciated, the precise nature of the signals that attract and localize mitochondria to particular sites in the neuron (a process referred to as "local mitochondria capture") remains largely undefined. Therefore, crucial questions in neurobiology are how mitochondria are recruited locally and what is the exact purpose they serve in this transition from stem cell to neuron.

In all cell types, mitochondria are extremely dynamic organelles that travel long distances along microtubules via forward molecular motors of the kinesin family and reverse molecular motors of the dynein family (Misgeld and Schwarz, 2017; Sheng, 2017; Gumy and Hoogenraad, 2018; Sweeney and Holzbaur, 2018). Because of the large distances spanned by neurites, cargos and organelles can take hours or even days to reach the most distal ends of a neuron, such as the axons' terminal branches, even with the fastest forms of molecular transport. Some of the basic processes controlling the anterograde and retrograde movement of mitochondria have been recently revealed, yet our understanding of the mechanisms that ensure mitochondrial distribution and turnover across complex neuronal geometries are still rudimentary. For example, it is now clear that mitochondrial positioning in developing axonal terminals is required to sculpt the axonal architecture. One protein involved in mitochondrial positioning is the mitochondrial anchor protein Syntaphilin, which is recruited to mitochondria to ensure their docking locally (Kang et al., 2008). Manipulations of Syntaphilin levels leading to exaggerated mitochondrial motility or immobilization cause a decrease or an increase in axonal branching, respectively (Courchet et al., 2013). Disruption of a kinase pathway composed of the polarity kinase LKB1 and the AMPK-related kinase NUAK1 also dramatically increases mitochondria motility in the axon, preventing their dwelling at immature presynaptic sites by an unknown molecular mechanism (Courchet et al., 2013). The net result is a decrease of terminal branch complexity both in vitro and in vivo (Fig. 1).

How do mitochondria know when and where to stop their movement? Experiments conducted in vitro have suggested that mitochondrial distribution along the axon is in part controlled by local changes of $\mathrm{Ca}^{2+}$ concentration. This involves the $\mathrm{Ca}^{2+}$ binding GTPases Mirol and 2, which reside on the outer mitochondrial membrane and, together with Milton/TRAKs proteins, 
mediate mitochondria binding to motor proteins (MacAskill et al., 2009). The current model suggests that local $\mathrm{Ca}^{2+}$ rise at synapses induces conformational changes in Miro1 resulting in mitochondrial stalling, either by causing detachment from microtubules or by preventing the motoradaptor interaction (MacAskill et al., 2009; Wang and Schwarz, 2009). While this model provides some mechanistic control over mitochondrial trafficking/ immobilization in an activity $\left(\mathrm{Ca}^{2+}\right)$ dependent manner, recent reports argue against this being the primary mechanism regulating mitochondrial trafficking in neurons in vivo. Imaging experiments performed on either the intact mouse cortex or retina raise the intriguing possibility that additional mechanisms may significantly contribute to mitochondrial positioning once neurons have progressed through development and reached maturation, as exemplified by a sharp drop in motility and a virtual lack of $\mathrm{Ca}^{2+}$ sensitivity of the mitochondrial population (Faits et al., 2016; Lewis et al., 2016; Wehnekamp et al., 2019).

What is the significance of mitochondrial distribution and positioning in fueling local neuronal mechanisms? As a result of their complex morphology, neurons have evolved specialized mechanisms within their subcompartments (dendrites, axons, dendritic spines, and axonal terminals) to ensure stringent regulation of basic cellular functions. One such compartmentalized mechanism, local protein synthesis, is observed in both the axonal and somatodendritic compartments and is critical for neurite development, maintenance, synaptic plasticity, and memory formation (Rangaraju et al., 2017, 2019). Protein synthesis requires a tremendous amount of energy, and little was known about how this need is met locally in dendrites and spines until recently. Recent studies combining conventional and superresolution microscopy coupled with methods to experimentally manipulate local mitochondrial function have demonstrated that spatially stable dendritic mitochondrial compartments fuel local translation during synaptic plasticity within spatially confined boundaries (Rangaraju et al., 2019). These findings show that, in addition to the presence of localized translational machinery in dendrites, local compartments of energy exist to fuel local translation during synaptic plasticity (Fig. 2).

Mitochondrial proteins are known to constitute a significant fraction of locally synthesized proteins in neurons. Transcriptomic analysis of the synaptic neuropil revealed that many of the dendritically localized mRNA transcripts encode mitochondrial proteins of nuclear origin (Miyashiro et al., 1994; Moccia et al., 2003; Zhong et al., 2006; Cajigas et al., 2012). Local mitochondrial protein synthesis has also been identified in axons (Shigeoka et al., 2016), and was shown to be important for mitochondrial morphology and membrane potential (Yoon et al., 2012; Cioni et al., 2019). Further studies will provide insights into the significance of these locally synthesized mitochondrial proteins in neuronal function and the relevance of mitochondrial function in local protein synthesis (Rossoll and Bassell, 2019).

\section{Mitochondrial dynamics and the control of compartment-specific mitochondrial function}

The morphology of a mitochondrion has been linked to its function, and regulation of this parameter is tightly controlled in many cell types (Picard et al., 2013; for review, see Liesa and Shirihai, 2013). Interestingly, cortical neurons display distinct mitochondrial morphology in their dendrites and axons (Popov et al., 2005; Chang and Reynolds, 2006; Dickey and Strack, 2011). In dendrites, mitochondria are elongated, overlapping with high density, whereas in axons, mitochondria are uniformly small, individual units localized to specific positions. This observation raises a number of intriguing questions: Is this important for neuronal development? Does it underlie the function of these distinct neuronal compartments? What are the molecular mechanisms controlling mitochondrial morphology in dendrites and axons?

Mitochondrial fission and fusion are the two major competing processes regulating mitochondrial morphology in the cell, and many of the proteins mediating these processes are conserved across species (Chen and Chan, 2009). In mammalian cells, mitochondrial fission occurs when the GTPase Drp1 is recruited from the cytosol to the outer mitochondrial membrane via one of the four known "receptors": MFF, FIS1, MIEF1, and MIEF2 (Gandre-Babbe and van der Bliek, 2008; Otera et al., 2010; Losón et al., 2013; Osellame et al., 2016). Drp1-directed constriction, in conjunction with the cytoskeleton and endoplasmic reticulum, leads to scission of the mitochondria (De Vos et al., 2005; Hatch et al., 2016). Fusion, on the other hand, is mediated by two distinct families of GTPases at the outer and inner membrane: MFN1/2 and OPA1 (Chen et al., 2003; Lee et al., 2004).

Recent work showed that loss of Mitochondrial Fission Factor (MFF) activity, via shRNA knockdown, increases axonal mitochondrial length and occupancy without altering dendritic mitochondrial morphology or occupancy, demonstrating that MFF-mediated fission is the main driver of the small mitochondrial size observed in the axon (Lewis et al., 2018). This is surprising, given that MFF decorates both axonal and dendritic mitochondria, and it suggests that either MFF or Drp1 is differentially regulated in these compartments to give rise to the high level of fission observed in the axon. While much work will be 
needed to elucidate the molecular mechanisms controlling axonal fission, knockdown of MFF provided a tool to determine the role of mitochondrial size for axonal development and function.

Interestingly, reduced MFF-mediated fission did not affect axonal mitochondrial trafficking or positioning to presynaptic sites, nor did it reduce mitochondrial membrane potential or mitochondrial ATP levels. Instead, the increase in mitochondrial size led to enhanced presynaptic calcium buffering via mitochondrial calcium uniporter-dependent entry into the mitochondria following neuronal activity. This increased mitochondrial $\mathrm{Ca}^{2+}$ buffering reduced synaptic vesicle (SV) fusion and neurotransmitter release at presynaptic sites that contained mitochondria and reduced axonal branching in vivo. These results, in addition to previous work, demonstrate the importance of mitochondrial positioning and size in axonal development (Kwon et al., 2016; Lewis et al., 2016; Smit-Rigter et al., 2016; Vaccaro et al., 2017), and represent a possible mechanism for the regulation of neurotransmitter release at individual boutons along the same axon. Interestingly, mitochondrial positioning and size have also been implicated in dendritic development and maintenance, and spine dynamics (Li et al., 2004; Dickey and Strack, 2011; Faits et al., 2016; López-Doménech et al., 2016; Divakaruni et al., 2018).

Future directions lie in understanding how different neuronal subtypes coordinate the balance between mitochondrial fission and fusion to drive distinct compartmentalization within axons and dendrites, and how aging and neurodegeneration affect this balance leading to neuronal dysfunction.

\section{Mitochondria as master regulators of synaptic function}

Local ATP production and $\mathrm{Ca}^{2+}$ regulation to support synaptic function

Given the high energy demand of the brain, early studies sought to identify the neuronal mechanisms that account for most of its energy burden. Theoretical computations pointed to ionic homeostasis following action potential propagation as the largest energy consumer (Attwell and Laughlin, 2001; Harris et al., 2012). Various recently developed optical biosensors have enabled the experimental validation of these theoretical results through ATP measurements in subneuronal compartments, especially at synapses. The biosensors include FRET-based sensors, such as ATeam (Imamura et al., 2009); ratiometric sensors, such as Perceval (Berg et al., 2009; Tantama et al., 2013); singlewavelength sensors, such as iATPSnFR (Lobas et al., 2019); and luciferase-based luminescent sensors, such as Syn-ATP (Rangaraju et al., 2014). Syn-ATP provided the first experimental estimate on the energy burden of presynaptic function and demonstrated that most of the ATP is consumed during SV recycling at presynaptic terminals (Rangaraju et al., 2014). In contrast, what accounts for the ATP burden in postsynaptic compartments remains unclear, but protein synthesis-dependent synaptic plasticity is a contender (Rangaraju et al., 2019). The above study has opened up a new set of unexplored questions on the local metabolic demands and its regulation in synaptic function.

Because of the high energy costs of synaptic activity, the mechanisms that perform local ATP synthesis are of particular importance for synaptic function. The use of the previously discussed ATP biosensors in combination with pharmacological manipulations revealed that neuronal ATP generation is largely driven by the activity-dependent uptake of glucose, which is metabolized by both glycolysis and oxidative phosphorylation, in presynaptic terminals (Rangaraju et al., 2014; Pathak et al., 2015; Ashrafi et al., 2017). Even brief perturbations in mitochondrial (or glycolytic)
ATP synthesis result in insufficient SV recycling and subsequent defects in synaptic transmission. Accordingly, the presence or absence of mitochondria at presynaptic terminals results in ATPdependent differences in SV release probabilities following multiple trains of stimulation (Sun et al., 2013). In dendritic spines, mitochondrial ATP synthesis, and not glycolysis, predominantly fuels protein synthesis-dependent synaptic plasticity (Rangaraju et al., 2019). Local perturbation of mitochondrial function abolishes both local protein synthesis and spine morphological plasticity. These studies underscore the importance of mitochondria in generating ATP at synapses. However, the molecular mechanisms that induce mitochondrial ATP synthesis in response to local synaptic activity are still relatively understudied.

Mitochondria also control synaptic $\mathrm{Ca}^{2+}$ homeostasis, which is critical for SV release. Recent studies using a genetically encoded $\mathrm{Ca}^{2+}$ indicator together with a pHluorin-based SV exocytosis sensor showed that mitochondria-free presynaptic terminals have higher presynaptic $\mathrm{Ca}^{2+}$ levels and SV release than mitochondria-occupied ones (Kwon et al., 2016; Vaccaro et al., 2017). Reduced mitochondrial $\mathrm{Ca}^{2+}$ uptake results in higher spontaneous and asynchronous SV release and impaired shortterm plasticity (Gazit et al., 2016; Kwon et al., 2016). Overall, it is clear that both mitochondrial ATP production and $\mathrm{Ca}^{2+}$ clearance are important for synaptic transmission (Figs. 1, 2). Furthermore, previous studies showed that mitochondrial $\mathrm{Ca}^{2+}$ can promote ATP synthesis by activating multiple components of the TCA cycle and OXPHOS supercomplexes in many cell types, including in neurons (Jouaville et al., 1999; Kann and Kovács, 2007; Griffiths and Rutter, 2009; Llorente-Folch et al., 2013).

In the future, elucidating the molecular mechanisms of local ATP synthesis and $\mathrm{Ca}^{2+}$ handling by mitochondria within local neuronal compartments is warranted. It also remains to be investigated whether these mechanisms are specialized according to the particular needs of the local neuronal compartments.

\section{Interorganelle contact sites and dendritic $\mathrm{Ca}^{2+}$ control}

Mitochondria regulate cytoplasmic $\mathrm{Ca}^{2+}$ levels in conjunction with the ER. The ER is composed of a continuous lipid bilayer that stretches throughout the neuron (Lindsey and Ellisman, 1985; Terasaki et al., 1994; Cui-Wang et al., 2012) and even extends into the tips of spines as either a simple smooth ER tubule or a spine apparatus (Spacek and Harris, 1997; Holbro et al., 2009). In addition to its role as a platform for lipid synthesis and protein transport, the $\mathrm{ER}$ acts as a $\mathrm{Ca}^{2+}$ repository that releases $\mathrm{Ca}^{2+}$ to the cytoplasm in response to neuronal inputs that activate either inositol trisphosphate receptors or ryanodine receptors in the ER membrane. The released $\mathrm{Ca}^{2+}$ is required for neuronal maturation and synaptic plasticity (Miyata et al., 2000; Johenning et al., 2015; Lee et al., 2016). Importantly, mitochondria buffer the $\mathrm{Ca}^{2+}$ released from the ER via the mitochondrial calcium uniporter, which resides on the inner mitochondrial membrane. Because mitochondrial calcium uniporter allows $\mathrm{Ca}^{2+}$ uptake only when the outer mitochondrial membrane side is exposed to a high $\mathrm{Ca}^{2+}$ concentration, proximity to the $\mathrm{ER}$ is essential for mitochondrial $\mathrm{Ca}^{2+}$ uptake (Csordás et al., 2010; Giacomello et al., 2010).

The contact between mitochondria and ER (mitochondria-ER contact sites [MERCSs]) is one of the most prominent interorganelle contacts (Valm et al., 2017). Although MERCSs have been observed in synaptosomes since the 1980s (McGraw et al., 1980), high-throughput serial electron microscopy techniques have recently confirmed that the ER and mitochondria have extensive contacts throughout neurons (Wu et al., 2017; Lee et al., 2018). 
Recent identification of the mammalian ER-mitochondria tethering protein PDZD8 has enabled testing the functional roles of these contacts. Knockdown of PDZD8 drastically reduces mitochondrial uptake of $\mathrm{Ca}^{2+}$ after synaptically induced $\mathrm{Ca}^{2+}$ release from the ER. The net outcome of altered $\mathrm{Ca}^{2+}$ transfer between organelles is an upregulation of cytoplasmic $\mathrm{Ca}^{2+}$ concentration in dendrites (Hirabayashi et al., 2017), suggesting that the extent of MERCSs can regulate cytoplasmic $\mathrm{Ca}^{2+}$ dynamics upon synaptic stimulation (Fig. 2).

In addition to $\mathrm{Ca}^{2+}$ transfer, MERCSs are implicated in a variety of cellular processes, such as membrane biogenesis, through the exchange of phospholipids between the mitochondria and ER (Csordás et al., 2018; Petrungaro and Kornmann, 2019). Dysregulation of MERCSs has been observed in mouse models of neurodegenerative diseases, and in patients with neurodegenerative diseases, such as Alzheimer's and Parkinson's (Area-Gomez and Schon, 2016; Lee et al., 2018). Therefore, it is of particular interest to reveal the physiological roles of these contacts in neurons. However, to date, only a few studies have investigated the role of the MERCSs in neurons (Lim et al., 2015; Hirabayashi et al., 2017; Gómez-Suaga et al., 2019). Given that these observations are limited to in vitro studies, the roles of MERCSs in neurons in vivo in the context of neural circuit remain to be elucidated.

\section{Mitochondrial dynamics in adult neurogenesis}

In contrast to most regions in the adult brain, the dentate gyrus of the hippocampus is endowed with radial glia-like neural stem cells and progenitor cells (NSPCs) that give rise to new neurons throughout one's life (Ming and Song, 2011). The generation and maturation of new neurons are shaped by sensory inputs and experiences via the activity of local interneurons (Song et al., 2012; Yeh et al., 2018). This process ultimately promotes new neuron integration into the preexisting network (Bergami et al., 2015; Temprana et al., 2015; Alvarez et al., 2016) and has important implications for cognition (Toda and Gage, 2018). Mechanisms controlling the proliferative capacity of NSPCs, the survival of newly generated neurons, and ultimately their connectivity pattern play key roles in ensuring life-long neurogenesis.

While NSPCs of embryonic origin derive most of their energy from glycolysis (Khacho et al., 2016), recent work focused on NSPCs in the adult brain provides new evidence that mitochondria can regulate specific steps along this neurogenic lineage. In particular, changes in the structure and function of the mitochondrial network of adult NSPCs accompany or even instruct specific metabolic switches underlying the genesis of adult-born neurons and, possibly, their evolving connectivity. A complete ultrastructural reconstruction of a single radial glia-like neural stem cell revealed numerous mitochondria distributed throughout its apical processes, including those directly contacting local blood vessels (Moss et al., 2016). This suggests that mitochondrial positioning in NSPCs may play an important metabolic role in regulating stem cell maintenance and fate. In line with this notion, recent single-cell RNA sequencing studies suggest that mitochondrial fatty acid $\beta$-oxidation is central for the energy metabolism of adult NSPCs (Shin et al., 2015), particularly for controlling their activation state (Stoll et al., 2015; Knobloch et al., 2017). At the early stages of cell activation and ensuing proliferation, genes involved in oxidative phosphorylation are upregulated. This suggests that mitochondrial metabolism is important during the proliferative steps of adult hippocampal NSPCs leading to the production of new neurons (Shin et al.,
2015; Beckervordersandforth et al., 2017). Yet the extent to which such functional gene expression changes are mirrored by remodeling the mitochondrial network during cell division and differentiation of a neuron is unclear.

Once generated, the young neurons pass through periods of significant morphological and functional plasticity before reaching complete maturity (Jahn and Bergami, 2018). While it is assumed that many of the principles that apply to the maturation of developmentally generated neurons, particularly with regard to mitochondrial dynamics and trafficking (Misgeld and Schwarz, 2017), also apply to adult-born hippocampal neurons, there is little evidence available. Nonetheless, we do know that the morphological development of adult-born neurons in vivo is accompanied by a substantial remodeling of mitochondrial networks and that normal dendritogenesis requires the GTPase Drp1 (Steib et al., 2014). While this evidence points to the significance of mitochondria in regulating morphological aspects of neuronal lineage progression, our current understanding of the underlying mechanisms is still rudimentary. In particular, it is not clear whether and how metabolic adaptation of the mitochondrial network architecture, for instance, via regulated fusion-fission dynamics and organelle positioning, contributes to synaptic maturation, establishment of connectivity, and plasticity in new neurons (Fig. 1).

\section{Alteration of mitochondrial function and dynamics in neurodegeneration}

Metabolic adaptation to mitochondrial dysfunction

As noted in previous sections, the mitochondrial network is continuously sculpted by coordinated mitochondrial fusion-fission dynamics in mammalian neurons. Regulated changes in the balance of these dynamics lead to more fragmented or elongated mitochondrial morphologies, and this is regarded as an important form of metabolic plasticity required to meet the evolving metabolic needs of cells (Mishra and Chan, 2016). Disrupted dynamics result in mitochondrial dysfunction, and such disruption is associated with neurodegeneration (Chen et al., 2007; Kageyama et al., 2012; Lee et al., 2012; Misko et al., 2012). Surprisingly, the precise metabolic consequences of mitochondrial dysfunction in neurons in vivo are unclear. In brain tissue, the ability to adapt cellular metabolism to challenging conditions is generally restricted to glia, given the central function of these cells in supplying energy metabolites to neurons for fueling synaptic transmission (Pellerin and Magistretti, 1994; Bélanger et al., 2011; Fünfschilling et al., 2012) and their competence in sustaining glycolytic metabolism for extended periods of time (Supplie et al., 2017). In disease, the metabolic plasticity of astrocytes is emphasized by their unique ability to reversibly adapt the structure of their mitochondrial network via regulated fusion-fission dynamics and to efficiently rewire their mitochondrial metabolism in vivo (Motori et al., 2013; Polyzos et al., 2019). In contrast, it is still unknown whether neurons exhibit similar metabolic plasticity in response to mitochondrial dysfunction in vivo and which pathways are primarily affected. Identifying potential tissue- and cell-specific pathways underlying metabolic rewiring in neurons may lead to specific interventions aimed at preventing neuronal death in many mitochondrial diseases (Fig. 1).

\section{Mitochondria in neurodegeneration and repair}

Given the complex morphology of neurons, and that they must essentially last for the entire lifespan of the organism, ensuring optimal distribution of mitochondria is critical for these cells. Thus, it is not surprising that numerous neurodegenerative dis- 
eases have been related to a defect in mitochondrial transport (Schon and Przedborski, 2011; Misgeld and Schwarz, 2017). For example, experimental mouse models of amyotrophic lateral sclerosis showed an impairment of mitochondrial transport in motor neurons expressing the disease-related SOD1 mutations (De Vos et al., 2007; Shi et al., 2010), whereas alteration of the PINK/Parkin pathways that regulate mitophagy by modulating mitochondrial transport has been linked to Parkinson's disease (Wang et al., 2011).

Mitochondrial dynamics are not only key to neurodegeneration but also to neuroregeneration. Some of the strongest evidence for the role of mitochondria in neuronal repair comes from the study in retinal ganglion cells (RGCs) (Cartoni et al., 2016). RGC neurons extend their axon from the eye to their targets in the brain via the optic nerve and therefore can be specifically damaged surgically by nerve crush. These neurons can also be easily manipulated genetically by viral injection into the eye (a procedure called intravitreal injection). These characteristics have established RGCs as a formidable platform to study the mechanisms of axonal regeneration and neuroprotection (Park et al., 2008; Sun et al., 2011). A striking feature that makes these neurons especially relevant to study the role of mitochondria in degeneration and regeneration is their extreme sensitivity to mitochondrial dysfunction. This is highlighted by several mitochondria-related optic neuropathies characterized by a highly selective degeneration of RGCs leading to vision loss. For example, Leber's hereditary optic neuropathy is caused by mutations in genes of the mitochondrial DNA encoding one of the NADH:ubiquinone oxidoreductase subunits, which impairs the function of complex I of the oxidative phosphorylation chain leading to the degeneration of RGCs exclusively (Wallace et al., 1999; Kirches, 2011; Wallace and Lott, 2017). Similarly, dominant optic atrophy is caused by mutations in the optic atrophy 1 protein (Opal) that regulates mitochondrial fusion and cristae maintenance (Alexander et al., 2000; Olichon et al., 2006). Although in some subclasses of dominant optic atrophy the degeneration appears to affect other type of neurons (Amati-Bonneau et al., 2009), RGCs are the only cell type affected by degeneration in the vast majority of dominant optic atrophy patients.

While studying RGC degeneration and regeneration following optic nerve crush, Cartoni et al. (2016) reported that a mitochondrial outer membrane protein called Armadillo Repeat Containing X-Linked 1 (Armcx1) regulates mitochondrial transport in axons and its deletion suppresses the regeneration that normally occurs after optic nerve crush in animals with deletion of PTEN and SOCS3. Importantly, overexpression of Armcx1 promoted RGC axonal regeneration and neuroprotection and its localization to mitochondria was necessary for this process (Cartoni et al., 2016). This study and others in different systems (Han et al., 2016; Zhou et al., 2016) strongly suggest the regulation of mitochondrial distribution along axons as a key mechanism for neuronal repair.

The importance of mitochondrial distribution in RGC is not only restricted to injury. In intact adult optic nerve, mitochondria accumulate in the proximal part of the nerve, the optic nerve head, where unmyelinated RGC axons have left the retina (Minckler et al., 1976; Bristow et al., 2002; Barron et al., 2004). The epicenter of RGC axon degeneration in glaucoma is the optic nerve head, therefore warranting the study of this mitochondrial compartmentalization (Nickells et al., 2012). The function and regulatory mechanisms of the axonal mitochondria compartmentalization are unknown. However, the existence of this subcellular mitochondrial heterogeneity suggests that a specific population of mitochondria is sequestrated at this location to perform a specific function. This uneven mitochondrial distribution along RGC axons in the optic nerve constitutes one of the many challenges the mitochondrial transport machinery faces to ensure precise distribution of mitochondria.

In conclusion, mitochondrial function is required throughout a neuron's life, including birth, development, synaptic transmission, and repair. Mitochondrial ATP production and $\mathrm{Ca}^{2+}$ clearance are key regulators of synaptic function and proteostasis in neurons. Consequently, impaired mitochondrial transport, fusion-fission, and activity lead to abnormal neurite branching, synaptic dysfunction, degeneration, and reduced regeneration. Further studies using novel imaging techniques to measure core mitochondrial functions will enhance our understanding of the role of mitochondria in both physiological and pathophysiological conditions.

\section{References}

Alexander C, Votruba M, Pesch UE, Thiselton DL, Mayer S, Moore A, Rodriguez M, Kellner U, Leo-Kottler B, Auburger G, Bhattacharya SS, Wissinger B (2000) OPAl, encoding a dynamin-related GTPase, is mutated in autosomal dominant optic atrophy linked to chromosome 3q28. Nat Genet 26:211-215.

Alvarez DD, Giacomini D, Yang SM, Trinchero MF, Temprana SG, Büttner KA, Beltramone N, Schinder AF (2016) A disynaptic feedback network activated by experience promotes the integration of new granule cells. Science 354:459-465.

Amati-Bonneau P, Milea D, Bonneau D, Chevrollier A, Ferré M, Guillet V, Gueguen N, Loiseau D, de Crescenzo MA, Verny C, Procaccio V, Lenaers G, Reynier P (2009) OPA1-associated disorders: phenotypes and pathophysiology. Int J Biochem Cell Biol 41:1855-1865.

Area-Gomez E, Schon EA (2016) Mitochondria-associated ER membranes and Alzheimer disease. Curr Opin Genet Dev 38:90-96.

Ashrafi G, Wu Z, Farrell RJ, Ryan TA (2017) GLUT4 mobilization supports energetic demands of active synapses. Neuron 93:606-615.e3.

Attwell D, Laughlin SB (2001) An energy budget for signaling in the grey matter of the brain. J Cereb Blood Flow Metab 21:1133-1145.

Barron MJ, Griffiths P, Turnbull DM, Bates D, Nichols P (2004) The distributions of mitochondria and sodium channels reflect the specific energy requirements and conduction properties of the human optic nerve head. Br J Ophthalmol 88:286-290.

Beckervordersandforth R, Ebert B, Schäffner I, Moss J, Fiebig C, Shin J, Moore DL, Ghosh L, Trinchero MF, Stockburger C, Friedland K, Steib K, von Wittgenstein J, Keiner S, Redecker C, Hölter SM, Xiang W, Wurst W, Jagasia R, Schinder AF, et al. (2017) Role of mitochondrial metabolism in the control of early lineage progression and aging phenotypes in adult hippocampal neurogenesis. Neuron 93:560-573.e6.

Bélanger M, Allaman I, Magistretti PJ (2011) Brain energy metabolism: focus on astrocyte-neuron metabolic cooperation. Cell Metab 14:724-738.

Berg J, Hung YP, Yellen G (2009) A genetically encoded fluorescent reporter of ATP:ADP ratio. Nat Methods 6:161-166.

Bergami M, Masserdotti G, Temprana SG, Motori E, Eriksson TM, Göbel J, Yang SM, Conzelmann KK, Schinder AF, Götz M, Berninger B (2015) A critical period for experience-dependent remodeling of adult-born neuron connectivity. Neuron 85:710-717.

Bristow EA, Griffiths PG, Andrews RM, Johnson MA, Turnbull DM (2002) The distribution of mitochondrial activity in relation to optic nerve structure. Arch Ophthalmol 120:791-796.

Burté F, Carelli V, Chinnery PF, Yu-Wai-Man P (2015) Disturbed mitochondrial dynamics and neurodegenerative disorders. Nat Rev Neurol 11:11-24.

Cajigas IJ, Tushev G, Will TJ, tom Dieck S, Fuerst N, Schuman EM (2012) The local transcriptome in the synaptic neuropil revealed by deep sequencing and high-resolution imaging. Neuron 74:453-466.

Cartoni R, Norsworthy MW, Bei F, Wang C, Li S, Zhang Y, Gabel CV, Schwarz TL, He Z (2016) The mammalian-specific protein Armcxl regulates mitochondrial transport during axon regeneration. Neuron 92: 1294-1307.

Chang DT, Reynolds IJ (2006) Differences in mitochondrial movement and 
morphology in young and mature primary cortical neurons in culture. Neuroscience 141:727-736.

Chen H, Chan DC (2009) Mitochondrial dynamics-fusion, fission, movement, and mitophagy — in neurodegenerative diseases. Hum Mol Genet 18:R169-R176.

Chen H, Detmer SA, Ewald AJ, Griffin EE, Fraser SE, Chan DC (2003) Mitofusins Mfn1 and Mfn2 coordinately regulate mitochondrial fusion and are essential for embryonic development. J Cell Biol 160:189-200.

Chen H, McCaffery JM, Chan DC (2007) Mitochondrial fusion protects against neurodegeneration in the cerebellum. Cell 130:548-562.

Cioni JM, Lin JQ, Holtermann AV, Koppers M, Jakobs MA, Azizi A, TurnerBridger B, Shigeoka T, Franze K, Harris WA, Holt CE (2019) Late endosomes act as mRNA translation platforms and sustain mitochondria in axons. Cell 176:56-72.e15.

Courchet J, Lewis TL Jr, Lee S, Courchet V, Liou DY, Aizawa S, Polleux F (2013) Terminal axon branching is regulated by the LKB1-NUAK1 kinase pathway via presynaptic mitochondrial capture. Cell 153:15101525.

Csordás G, Várnai P, Golenár T, Roy S, Purkins G, Schneider TG, Balla T, Hajnóczky G (2010) Imaging interorganelle contacts and local calcium dynamics at the ER-mitochondrial interface. Mol Cell 39:121-132.

Csordás G, Weaver D, Hajnóczky G (2018) Endoplasmic reticulummitochondrial contactology: structure and signaling functions. Trends Cell Biol 28:523-540.

Cui-Wang T, Hanus C, Cui T, Helton T, Bourne J, Watson D, Harris KM, Ehlers MD (2012) Local zones of endoplasmic reticulum complexity confine cargo in neuronal dendrites. Cell 148:309-321.

De Vos KJ, Allan VJ, Grierson AJ, Sheetz MP (2005) Mitochondrial function and actin regulate dynamin-related protein 1-dependent mitochondrial fission. Curr Biol 15:678-683.

De Vos KJ, Chapman AL, Tennant ME, Manser C, Tudor EL, Lau KF, Brownlees J, Ackerley S, Shaw PJ, McLoughlin DM, Shaw CE, Leigh PN, Miller CC, Grierson AJ (2007) Familial amyotrophic lateral sclerosis-linked SOD1 mutants perturb fast axonal transport to reduce axonal mitochondria content. Hum Mol Genet 16:2720-2728.

Díaz-García CM, Mongeon R, Lahmann C, Koveal D, Zucker H, Yellen G (2017) Neuronal stimulation triggers neuronal glycolysis and not lactate uptake. Cell Metab 26:361-374.e4.

Dickey AS, Strack S (2011) PKA/AKAP1 and PP2A/B $\beta 2$ regulate neuronal morphogenesis via Drp1 phosphorylation and mitochondrial bioenergetics. J Neurosci 31:15716-15726.

Divakaruni SS, Van Dyke AM, Chandra R, LeGates TA, Contreras M, Dharmasri PA, Higgs HN, Lobo MK, Thompson SM, Blanpied TA (2018) Long-term potentiation requires a rapid burst of dendritic mitochondrial fission during induction. Neuron 100:860-875.e7.

Faits MC, Zhang C, Soto F, Kerschensteiner D (2016) Dendritic mitochondria reach stable positions during circuit development. Elife 5:e11583.

Fünfschilling U, Supplie LM, Mahad D, Boretius S, Saab AS, Edgar J, Brinkmann BG, Kassmann CM, Tzvetanova ID, Möbius W, Diaz F, Meijer D, Suter U, Hamprecht B, Sereda MW, Moraes CT, Frahm J, Goebbels S, Nave KA (2012) Glycolytic oligodendrocytes maintain myelin and longterm axonal integrity. Nature 485:517-521.

Gandre-Babbe S, van der Bliek AM (2008) The novel tail-anchored membrane protein Mff controls mitochondrial and peroxisomal fission in mammalian cells. Mol Biol Cell 19:2402-2412.

Gazit N, Vertkin I, Shapira I, Helm M, Slomowitz E, Sheiba M, Mor Y, Rizzoli S, Slutsky I (2016) IGF-1 receptor differentially regulates spontaneous and evoked transmission via mitochondria at hippocampal synapses. Neuron 89:583-597.

Giacomello M, Drago I, Bortolozzi M, Scorzeto M, Gianelle A, Pizzo P, Pozzan T (2010) $\mathrm{Ca}^{2+}$ hot spots on the mitochondrial surface are generated by $\mathrm{Ca}^{2+}$ mobilization from stores, but not by activation of store-operated $\mathrm{Ca}^{2+}$ channels. Mol Cell 38:280-290.

Gómez-Suaga P, Pérez-Nievas BG, Glennon EB, Lau DH, Paillusson S, Mórotz GM, Calì T, Pizzo P, Noble W, Miller CC (2019) The VAPBPTPIP51 endoplasmic reticulum-mitochondria tethering proteins are present in neuronal synapses and regulate synaptic activity. Acta Neuropathol Commun 7:35.

Goyal MS, Hawrylycz M, Miller JA, Snyder AZ, Raichle ME (2014) Aerobic glycolysis in the human brain is associated with development and neotenous gene expression. Cell Metab 19:49-57.

Griffiths EJ, Rutter GA (2009) Mitochondrial calcium as a key regulator of mitochondrial ATP production in mammalian cells. Biochim Biophys Acta 1787:1324-1333.

Gumy LF, Hoogenraad CC (2018) Local mechanisms regulating selective cargo entry and long-range trafficking in axons. Curr Opin Neurobiol 51:23-28.

Han SM, Baig HS, Hammarlund M (2016) Mitochondria localize to injured axons to support regeneration. Neuron 92:1308-1323.

Harris JJ, Jolivet R, Attwell D (2012) Synaptic energy use and supply. Neuron 75:762-777.

Hatch AL, Ji WK, Merrill RA, Strack S, Higgs HN (2016) Actin filaments as dynamic reservoirs for Drp1 recruitment. Mol Biol Cell 27:3109-3121.

Hirabayashi Y, Kwon SK, Paek H, Pernice WM, Paul MA, Lee J, Erfani P, Raczkowski A, Petrey DS, Pon LA, Polleux F (2017) ER-mitochondria tethering by PDZD8 regulates $\mathrm{Ca}(2+)$ dynamics in mammalian neurons. Science 358:623-630

Holbro N, Grunditz A, Oertner TG (2009) Differential distribution of endoplasmic reticulum controls metabotropic signaling and plasticity at hippocampal synapses. Proc Natl Acad Sci U S A 106:15055-15060.

Imamura H, Nhat KP, Togawa H, Saito K, Iino R, Kato-Yamada Y, Nagai T, Noji H (2009) Visualization of ATP levels inside single living cells with fluorescence resonance energy transfer-based genetically encoded indicators. Proc Natl Acad Sci U S A 106:15651-15656.

Jahn HM, Bergami M (2018) Critical periods regulating the circuit integration of adult-born hippocampal neurons. Cell Tissue Res 371:23-32.

Jang S, Nelson JC, Bend EG, Rodríguez-Laureano L, Tueros FG, Cartagenova L, Underwood K, Jorgensen EM, Colón-Ramos DA (2016) Glycolytic enzymes localize to synapses under energy stress to support synaptic function. Neuron 90:278-291.

Johenning FW, Theis AK, Pannasch U, Rückl M, Rüdiger S, Schmitz D (2015) Ryanodine receptor activation induces long-term plasticity of spine calcium dynamics. PLoS Biol 13:e1002181.

Jouaville LS, Pinton P, Bastianutto C, Rutter GA, Rizzuto R (1999) Regulation of mitochondrial ATP synthesis by calcium: evidence for a long-term metabolic priming. Proc Natl Acad Sci U S A 96:13807-13812.

Kageyama Y, Zhang Z, Roda R, Fukaya M, Wakabayashi J, Wakabayashi N, Kensler TW, Reddy PH, Iijima M, Sesaki H (2012) Mitochondrial division ensures the survival of postmitotic neurons by suppressing oxidative damage. J Cell Biol 197:535-551.

Kang JS, Tian JH, Pan PY, Zald P, Li C, Deng C, Sheng ZH (2008) Docking of axonal mitochondria by syntaphilin controls their mobility and affects short-term facilitation. Cell 132:137-148.

Kann O, Kovács R (2007) Mitochondria and neuronal activity. Am J Physiol Cell Physiol 292:C641-C657.

Kety SS (1957) The general metabolism of the brain in vivo. In: Metabolism of the nervous system, pp 221-237. New York: Pergamon.

Khacho M, Clark A, Svoboda DS, Azzi J, MacLaurin JG, Meghaizel C, Sesaki H, Lagace DC, Germain M, Harper ME, Park DS, Slack RS (2016) Mitochondrial dynamics impacts stem cell identity and fate decisions by regulating a nuclear transcriptional program. Cell Stem Cell 19:232-247.

Khacho M, Harris R, Slack RS (2019) Mitochondria as central regulators of neural stem cell fate and cognitive function. Nat Rev Neurosci 20:34-48.

Kirches E (2011) LHON: mitochondrial mutations and more. Curr Genom 12:44-54.

Knobloch M, Pilz GA, Ghesquière B, Kovacs WJ, Wegleiter T, Moore DL, Hruzova M, Zamboni N, Carmeliet P, Jessberger S (2017) A fatty acid oxidation-dependent metabolic shift regulates adult neural stem cell activity. Cell Rep 20:2144-2155.

Kuzawa CW, Chugani HT, Grossman LI, Lipovich L, Muzik O, Hof PR, Wildman DE, Sherwood CC, Leonard WR, Lange N (2014) Metabolic costs and evolutionary implications of human brain development. Proc Natl Acad Sci U S A 111:13010-13015.

Kwon SK, Sando R 3rd, Lewis TL, Hirabayashi Y, Maximov A, Polleux F (2016) LKB1 regulates mitochondria-dependent presynaptic calcium clearance and neurotransmitter release properties at excitatory synapses along cortical axons. PLoS Biol 14:e1002516.

Lee A, Hirabayashi Y, Kwon SK, Lewis TL Jr, Polleux F (2018) Emerging roles of mitochondria in synaptic transmission and neurodegeneration. Curr Opin Physiol 3:82-93.

Lee KF, Soares C, Thivierge JP, Béique JC (2016) Correlated synaptic inputs drive dendritic calcium amplification and cooperative plasticity during clustered synapse development. Neuron 89:784-799.

Lee S, Sterky FH, Mourier A, Terzioglu M, Cullheim S, Olson L, Larsson NG 
(2012) Mitofusin 2 is necessary for striatal axonal projections of midbrain dopamine neurons. Hum Mol Genet 21:4827-4835.

Lee YJ, Jeong SY, Karbowski M, Smith CL, Youle RJ (2004) Roles of the mammalian mitochondrial fission and fusion mediators Fis1, Drp1, and Opa1 in apoptosis. Mol Biol Cell 15:5001-5011.

Lewis TL Jr, Turi GF, Kwon SK, Losonczy A, Polleux F (2016) Progressive decrease of mitochondrial motility during maturation of cortical axons in vitro and in vivo. Curr Biol 26:2602-2608.

Lewis TL Jr, Kwon SK, Lee A, Shaw R, Polleux F (2018) MFF-dependent mitochondrial fission regulates presynaptic release and axon branching by limiting axonal mitochondria size. Nat Commun 9:5008.

Li Z, Okamoto K, Hayashi Y, Sheng M (2004) The importance of dendritic mitochondria in the morphogenesis and plasticity of spines and synapses. Cell 119:873-887.

Liesa M, Shirihai OS (2013) Mitochondrial dynamics in the regulation of nutrient utilization and energy expenditure. Cell Metab 17:491-506.

Lim Y, Cho IT, Schoel LJ, Cho G, Golden JA (2015) Hereditary spastic paraplegia-linked REEP1 modulates endoplasmic reticulum/mitochondria contacts. Ann Neurol 78:679-696.

Lindsey JD, Ellisman MH (1985) The neuronal endomembrane system: III. The origins of the axoplasmic reticulum and discrete axonal cisternae at the axon hillock. J Neurosci 5:3135-3144.

Llorente-Folch I, Rueda CB, Amigo I, del Arco A, Saheki T, Pardo B, Satrústegui J (2013) Calcium-regulation of mitochondrial respiration maintains ATP homeostasis and requires ARALAR/AGC1-malate aspartate shuttle in intact cortical neurons. J Neurosci 33:13957-13971, 13971a.

Lobas MA, Tao R, Nagai J, Kronschläger MT, Borden PM, Marvin JS, Looger LL, Khakh BS (2019) A genetically encoded single-wavelength sensor for imaging cytosolic and cell surface ATP. Nat Commun 10:711.

López-Doménech G, Higgs NF, Vaccaro V, Ros H, Arancibia-Cárcamo IL, MacAskill AF, Kittler JT (2016) Loss of dendritic complexity precedes neurodegeneration in a mouse model with disrupted mitochondrial distribution in mature dendrites. Cell Rep 17:317-327.

Losón OC, Song Z, Chen H, Chan DC (2013) Fis1, Mff, MiD49, and MiD51 mediate Drp1 recruitment in mitochondrial fission. Mol Biol Cell 24: $659-667$.

MacAskill AF, Rinholm JE, Twelvetrees AE, Arancibia-Carcamo IL, Muir J, Fransson A, Aspenstrom P, Attwell D, Kittler JT (2009) Mirol is a calcium sensor for glutamate receptor-dependent localization of mitochondria at synapses. Neuron 61:541-555.

Magistretti PJ, Allaman I (2015) A cellular perspective on brain energy metabolism and functional imaging. Neuron 86:883-901.

Magistretti PJ, Allaman I (2018) Lactate in the brain: from metabolic endproduct to signalling molecule. Nat Rev Neurosci 19:235-249.

Mattson MP, Gleichmann M, Cheng A (2008) Mitochondria in neuroplasticity and neurological disorders. Neuron 60:748-766.

McGraw CF, Somlyo AV, Blaustein MP (1980) Localization of calcium in presynaptic nerve terminals. an ultrastructural and electron microprobe analysis. J Cell Biol 85:228-241.

Minckler DS, Tso MO, Zimmerman LE (1976) A light microscopic, autoradiographic study of axoplasmic transport in the optic nerve head during ocular hypotony, increased intraocular pressure, and papilledema. Am J Ophthalmol 82:741-757.

Ming GL, Song H (2011) Adult neurogenesis in the mammalian brain: significant answers and significant questions. Neuron 70:687-702.

Mink JW, Blumenschine RJ, Adams DB (1981) Ratio of central nervous system to body metabolism in vertebrates: its constancy and functional basis. Am J Physiol 241:R203-R212.

Misgeld T, Schwarz TL (2017) Mitostasis in neurons: maintaining mitochondria in an extended cellular architecture. Neuron 96:651-666.

Mishra P, Chan DC (2016) Metabolic regulation of mitochondrial dynamics. J Cell Biol 212:379-387.

Misko AL, Sasaki Y, Tuck E, Milbrandt J, Baloh RH (2012) Mitofusin2 mutations disrupt axonal mitochondrial positioning and promote axon degeneration. J Neurosci 32:4145-4155.

Miyashiro K, Dichter M, Eberwine J (1994) On the nature and differential distribution of mRNAs in hippocampal neurites: implications for neuronal functioning. Proc Natl Acad Sci U S A 91:10800-10804.

Miyata M, Finch EA, Khiroug L, Hashimoto K, Hayasaka S, Oda SI, Inouye M, Takagishi Y, Augustine GJ, Kano M (2000) Local calcium release in dendritic spines required for long-term synaptic depression. Neuron 28: 233-244.
Moccia R, Chen D, Lyles V, Kapuya E, E Y, Kalachikov S, Spahn CM, Frank J, Kandel ER, Barad M, Martin KC (2003) An unbiased cDNA library prepared from isolated Aplysia sensory neuron processes is enriched for cytoskeletal and translational mRNAs. J Neurosci 23:9409-9417.

Moss J, Gebara E, Bushong EA, Sánchez-Pascual I, O’Laoi R, El M’Ghari I, Kocher-Braissant J, Ellisman MH, Toni N (2016) Fine processes of nestin-GFP-positive radial glia-like stem cells in the adult dentate gyrus ensheathe local synapses and vasculature. Proc Natl Acad Sci U S A 113:E2536-E2545.

Motori E, Puyal J, Toni N, Ghanem A, Angeloni C, Malaguti M, Cantelli-Forti G, Berninger B, Conzelmann KK, Götz M, Winklhofer KF, Hrelia S, Bergami M (2013) Inflammation-induced alteration of astrocyte mitochondrial dynamics requires autophagy for mitochondrial network maintenance. Cell Metab 18:844-859.

Nickells RW, Howell GR, Soto I, John SW (2012) Under pressure: cellular and molecular responses during glaucoma, a common neurodegeneration with axonopathy. Annu Rev Neurosci 35:153-179.

Olichon A, Guillou E, Delettre C, Landes T, Arnauné-Pelloquin L, Emorine LJ, Mils V, Daloyau M, Hamel C, Amati-Bonneau P, Bonneau D, Reynier P, Lenaers G, Belenguer P (2006) Mitochondrial dynamics and disease, OPA1. Biochim Biophys Acta 1763:500-509.

Osellame LD, Singh AP, Stroud DA, Palmer CS, Stojanovski D, Ramachandran R, Ryan MT (2016) Cooperative and independent roles of the Drp1 adaptors Mff, MiD49 and MiD51 in mitochondrial fission. J Cell Sci 129:2170-2181.

Otera H, Wang C, Cleland MM, Setoguchi K, Yokota S, Youle RJ, Mihara K (2010) Mff is an essential factor for mitochondrial recruitment of Drp1 during mitochondrial fission in mammalian cells. J Cell Biol 191: 1141-1158.

Park KK, Liu K, Hu Y, Smith PD, Wang C, Cai B, Xu B, Connolly L, Kramvis I, Sahin M, He Z (2008) Promoting axon regeneration in the adult CNS by modulation of the PTEN/mTOR pathway. Science 322:963-966.

Pathak D, Shields LY, Mendelsohn BA, Haddad D, Lin W, Gerencser AA, Kim H, Brand MD, Edwards RH, Nakamura K (2015) The role of mitochondrially derived ATP in synaptic vesicle recycling. J Biol Chem 290: 22325-22336.

Pellerin L, Magistretti PJ (1994) Glutamate uptake into astrocytes stimulates aerobic glycolysis: a mechanism coupling neuronal activity to glucose utilization. Proc Natl Acad Sci U S A 91:10625-10629.

Petrungaro C, Kornmann B (2019) Lipid exchange at ER-mitochondria contact sites: a puzzle falling into place with quite a few pieces missing. Curr Opin Cell Biol 57:71-76.

Picard M, Shirihai OS, Gentil BJ, Burelle Y (2013) Mitochondrial morphology transitions and functions: implications for retrograde signaling? Am J Physiol Regul Integr Comp Physiol 304:R393-R406.

Polyzos AA, Lee DY, Datta R, Hauser M, Budworth H, Holt A, Mihalik S, Goldschmidt P, Frankel K, Trego K, Bennett MJ, Vockley J, Xu K, Gratton E, McMurray CT (2019) Metabolic reprogramming in astrocytes distinguishes region-specific neuronal susceptibility in Huntington mice. Cell Metab 29:1258-1273.e11.

Popov V, Medvedev NI, Davies HA, Stewart MG (2005) Mitochondria form a filamentous reticular network in hippocampal dendrites but are present as discrete bodies in axons: a three-dimensional ultrastructural study. J Comp Neurol 492:50-65.

Rangaraju V, Calloway N, Ryan TA (2014) Activity-driven local ATP synthesis is required for synaptic function. Cell 156:825-835.

Rangaraju V, tom Dieck S, Schuman EM (2017) Local translation in neuronal compartments: how local is local? EMBO Rep 18:693-711.

Rangaraju V, Lauterbach M, Schuman EM (2019) Spatially stable mitochondrial compartments fuel local translation during plasticity. Cell 176: 73-84.e15.

Rossoll W, Bassell GJ (2019) Crosstalk of local translation and mitochondria: powering plasticity in axons and dendrites. Neuron 101:204-206.

Schon EA, Przedborski S (2011) Mitochondria: the next (neurode)generation. Neuron 70:1033-1053.

Sheng ZH (2017) The interplay of axonal energy homeostasis and mitochondrial trafficking and anchoring. Trends Cell Biol 27:403-416.

Sheng ZH, Cai Q (2012) Mitochondrial transport in neurons: impact on synaptic homeostasis and neurodegeneration. Nat Rev Neurosci 13: 77-93.

Shi P, Gal J, Kwinter DM, Liu X, Zhu H (2010) Mitochondrial dysfunction in amyotrophic lateral sclerosis. Biochim Biophys Acta 1802:45-51. 
Shigeoka T, Jung H, Jung J, Turner-Bridger B, Ohk J, Lin JQ, Amieux PS, Holt CE (2016) Dynamic axonal translation in developing and mature visual circuits. Cell 166:181-192.

Shin J, Berg DA, Zhu Y, Shin JY, Song J, Bonaguidi MA, Enikolopov G, Nauen DW, Christian KM, Ming GL, Song H (2015) Single-cell RNA-seq with waterfall reveals molecular cascades underlying adult neurogenesis. Cell Stem Cell 17:360-372.

Smit-Rigter L, Rajendran R, Silva CA, Spierenburg L, Groeneweg F, Ruimschotel EM, van Versendaal D, van der Togt C, Eysel UT, Heimel JA, Lohmann C, Levelt CN (2016) Mitochondrial dynamics in visual cortex are limited in vivo and not affected by axonal structural plasticity. Curr Biol 26:2609-2616.

Song J, Zhong C, Bonaguidi MA, Sun GJ, Hsu D, Gu Y, Meletis K, Huang ZJ, Ge S, Enikolopov G, Deisseroth K, Luscher B, Christian KM, Ming GL, Song H (2012) Neuronal circuitry mechanism regulating adult quiescent neural stem-cell fate decision. Nature 489:150-154.

Spacek J, Harris KM (1997) Three-dimensional organization of smooth endoplasmic reticulum in hippocampal CA1 dendrites and dendritic spines of the immature and mature rat. J Neurosci 17:190-203.

Steib K, Schäffner I, Jagasia R, Ebert B, Lie DC (2014) Mitochondria modify exercise-induced development of stem cell-derived neurons in the adult brain. J Neurosci 34:6624-6633.

Stoll EA, Makin R, Sweet IR, Trevelyan AJ, Miwa S, Horner PJ, Turnbull DM (2015) Neural stem cells in the adult subventricular zone oxidize fatty acids to produce energy and support neurogenic activity. Stem Cells 33:2306-2319.

Sun F, Park KK, Belin S, Wang D, Lu T, Chen G, Zhang K, Yeung C, Feng G, Yankner BA, He Z (2011) Sustained axon regeneration induced by codeletion of PTEN and SOCS3. Nature 480:372-375.

Sun T, Qiao H, Pan PY, Chen Y, Sheng ZH (2013) Motile axonal mitochondria contribute to the variability of presynaptic strength. Cell Rep 4:413-419.

Supplie LM, Düking T, Campbell G, Diaz F, Moraes CT, Götz M, Hamprecht B, Boretius S, Mahad D, Nave KA (2017) Respiration-deficient astrocytes survive as glycolytic cells in vivo. J Neurosci 37:4231-4242.

Sweeney HL, Holzbaur EL (2018) Motor proteins. Cold Spring Harb Perspect Biol 10:a021931.

Tantama M, Martínez-François JR, Mongeon R, Yellen G (2013) Imaging energy status in live cells with a fluorescent biosensor of the intracellular ATP-to-ADP ratio. Nat Commun 4:2550.

Temprana SG, Mongiat LA, Yang SM, Trinchero MF, Alvarez DD, Kropff E, Giacomini D, Beltramone N, Lanuza GM, Schinder AF (2015) Delayed coupling to feedback inhibition during a critical period for the integration of adult-born granule cells. Neuron 85:116-130.
Terasaki M, Slater NT, Fein A, Schmidek A, Reese TS (1994) Continuous network of endoplasmic reticulum in cerebellar Purkinje neurons. Proc Natl Acad Sci U S A 91:7510-7514.

Toda T, Gage FH (2018) Review: adult neurogenesis contributes to hippocampal plasticity. Cell Tissue Res 373:693-709.

Vaccaro V, Devine MJ, Higgs NF, Kittler JT (2017) Miro1-dependent mitochondrial positioning drives the rescaling of presynaptic $\mathrm{Ca}^{2+}$ signals during homeostatic plasticity. EMBO Rep 18:231-240.

Valm AM, Cohen S, Legant WR, Melunis J, Hershberg U, Wait E, Cohen AR, Davidson MW, Betzig E, Lippincott-Schwartz J (2017) Applying systems-level spectral imaging and analysis to reveal the organelle interactome. Nature 546:162-167.

Wallace DC, Lott MT (2017) Leber hereditary optic neuropathy: exemplar of an mtDNA disease. Handb Exp Pharmacol 240:339-376.

Wallace DC, Brown MD, Lott MT (1999) Mitochondrial DNA variation in human evolution and disease. Gene 238:211-230.

Wang X, Schwarz TL (2009) The mechanism of $\mathrm{Ca}^{2+}$-dependent regulation of kinesin-mediated mitochondrial motility. Cell 136:163-174.

Wang X, Winter D, Ashrafi G, Schlehe J, Wong YL, Selkoe D, Rice S, Steen J, LaVoie MJ, Schwarz TL (2011) PINK1 and Parkin target Miro for phosphorylation and degradation to arrest mitochondrial motility. Cell 147:893-906.

Wehnekamp F, Plucinska G, Thong R, Misgeld T, Lamb DC (2019) Nanoresolution real-time $3 \mathrm{D}$ orbital tracking for studying mitochondrial trafficking in vertebrate axons in vivo. Elife 8:655.

Wu Y, Whiteus C, Xu CS, Hayworth KJ, Weinberg RJ, Hess HF, De Camilli P (2017) Contacts between the endoplasmic reticulum and other membranes in neurons. Proc Natl Acad Sci U S A 114:E4859-E4867.

Yeh CY, Asrican B, Moss J, Quintanilla LJ, He T, Mao X, Cassé F, Gebara E, Bao H, Lu W, Toni N, Song J (2018) Mossy cells control adult neural stem cell quiescence and maintenance through a dynamic balance between direct and indirect pathways. Neuron 99:493-510.e4.

Yoon BC, Jung H, Dwivedy A, O’Hare CM, Zivraj KH, Holt CE (2012) Local translation of extranuclear lamin B promotes axon maintenance. Cell 148:752-764.

Zala D, Hinckelmann MV, Yu H, Lyra da Cunha MM, Liot G, Cordelières FP, Marco S, Saudou F (2013) Vesicular glycolysis provides on-board energy for fast axonal transport. Cell 152:479-491.

Zhong J, Zhang T, Bloch LM (2006) Dendritic mRNAs encode diversified functionalities in hippocampal pyramidal neurons. BMC Neurosci 7:17.

Zhou B, Yu P, Lin MY, Sun T, Chen Y, Sheng ZH (2016) Facilitation of axon regeneration by enhancing mitochondrial transport and rescuing energy deficits. J Cell Biol 214:103-119. 